\title{
EVALUATING LIVING STANDARD INDICATORS
}

\section{Nad’a Birčiaková ${ }^{1}$, Jana Stávková ${ }^{2}$, Veronika Antošová ${ }^{3}$}

\begin{abstract}
This paper deals with the evaluation of selected available indicators of living standards, divided into three groups, namely economic, environmental, and social. We have selected six countries of the European Union for analysis: Bulgaria, the Czech Republic, Hungary, Luxembourg, France, and Great Britain. The aim of this paper is to evaluate indicators measuring living standards and suggest the most important factors which should be included in the final measurement. We have tried to determine what factors influence each indicator and what factors affect living standards. We have chosen regression analysis as our main method. From the study of factors, we can deduce their impact on living standards, and thus the value of indicators of living standards. Indicators with a high degree of reliability include the following factors: size and density of population, health care and spending on education. Emissions of carbon dioxide in the atmosphere also have a certain lower degree of reliability.
\end{abstract}

\section{Keywords}

Living Standards, Indicators, Quality of Life, Well-being, European Union

\section{Introduction}

It is difficult to imagine anything of more interest than standard of living, a matter that is the subject of people's everyday thoughts. The existing idea of living standards is, however, full of contrasts, conflicts, and even contradictions. Without a general definition, diverse views differ and constitute a fragmented unit (Sen, 1989). Bennett (1937) expressed the idea that standard of living is highly complex and a very difficult concept to grasp. Cottam and Mangus (1942) agreed with this idea. According to them, some definitions of standard

\footnotetext{
${ }^{1}$ Mendel University in Brno, Faculty of Business and Economics, Zemědělská 1, 613 00, Brno, Czech Republic, E-mail: nada.birciakova@mendelu.cz.

${ }^{2}$ Mendel University in Brno, Faculty of Business and Economics, Zemědělská 1, 61300 Brno, Czech Republic, E-mail: jana.stavkova@mendelu.cz.

${ }^{3}$ Mendel University in Brno, Faculty of Business and Economics, Zemědělská 1, 61300 Brno, Czech Republic, E-mail: veronika.antosova@mendelu.cz.
} 
of living focus more on material consumption, while others emphasize contentment. However, there is no established definition that would be accepted by all without exception. There are a large number of fundamental differences in the methods of assessing living standards and the related quality of life. Nevertheless, only some of these have real credibility. You may be wealthy, but you are not content. You are content, but you are not able to lead the kind of life you want. You can have that life, but are not happy. You may be happy, but you lack other things. In short, the subject of standard of living is very complex.

The most widely used indicator of standard of living is the per capita gross domestic product. Many economists consider per capita GDP growth as the most important goal. However, Krugman and Wells (2012) argue that it is not sufficient for measuring human welfare and by itself it is not a suitable tool for policy decisions. GDP was never intended to measure wellbeing.

The term living standards is used for the expression of conditions in which a person or a nation lives, and which they also help to create. This concept has gradually developed various definitions which are primarily determined by the discipline in which a given definition was created. Consistency does not exist even within the discipline. Standard of living is often associated and sometimes confused with quality of life and prosperity. The main disciplines that deal with issues of living standards are first of all economics, then sociology and psychology. From an economic perspective, standard of living is measured in material terms, mostly at the state level (income, consumption and unemployment). Gross domestic product per capita is most commonly used for international comparison of general standards of living. Significant amounts of criticism with regard to this indicator has gradually accumulated within the professional community. This is based on the main idea that GDP per capita does not faithfully represent the real situation of the population, because it does not reflect many items that impact peoples' lives, and vice versa, it includes items which influence peoples' lives in a negative way. Consequently, criticism of criticism arises, which leads to intellectual struggle. For this reason many new alternative indicators are often created. This closes the vicious cycle, enabling GDP per capita to retain its strong position.

Gross domestic product is definitely a very important indicator of production. However, the wealth and living standards of the state depend not only on production efficiency, but also on other factors. For this reason, GDP should not be the only comprehensive indicator for evaluating the overall development of a country (Spěváček, 2005).

Gradually, various alternative indices were developed. The second half of the 20th century represented a period of discussion over the need to resolve the contentious points of GDP as an indicator of prosperity. Based on the activities of the UNO, OECD, World Bank, European Union, but also various other entities, new indicators were constructed. In one way or another, these complement the weaknesses of GDP per capita, or replace it entirely (Bleys, 2012). Such attitudes are the motivation for writing this paper. This paper aims to assess the explanatory power of selected indicators of living standards, to highlight their differences and their relationships. Our main objective is to suggest factors that should be included in the assessment of living standards. 


\section{Methods}

To achieve the objectives of this paper, we have selected six countries and used cluster analysis to analyse their GDP according to the expenditure method. Its aim was to group the individual EU members into clusters. This is a hierarchical form of clustering, comprising of subsets. Clusters are created on the basis of similarities, or on the contrary, of differences. There are several possible ways to measure separation or similarity. To cluster objects of interest, the nearest neighbour method was used, aka complete linkage. The distance between clusters is governed by the distance of the two outermost objects from different clusters (Hebák et al., 2005). The cluster analysis outcome is a dendrogram, which is a cluster diagram. The dendrogram reveals those that are similar and intercorrelated (Meloun, Militký, 2006).

From each cluster we have selected one representative in order to clearly see the differences in GDP among the countries. These representatives include the Czech Republic, Bulgaria, Great Britain, Luxembourg, Hungary, and France.

GDP is seen as a benchmark for comparing the level of the standard of living between this indicator and other indicators of living standards. The reference period for the monitoring of selected indicators in individual countries are the years 2000 to 2011.

We have divided individual indicators for the assessment of countries according to indicators of living standards into three groups, namely economic, environmental and social indicators.

Economic indicators are represented by the Genuine Savings Index (GSI). This index is based on the gross domestic savings and Global Competitiveness Index (GCI), which is in some measure an expression of economic productivity.

Environmental indicators include Ecological Footprint (EF), the Environmental Performance Index (EPI) and Happy Planet Index (HPI).

Social indicators include the Human Development Index (HDI) and Sustainable Society Index (SSI).

Several variables contribute to the value of individual indicators. Such variables may affect the creation of several indicators from the three groups mentioned above. For the purposes of monitoring the relationships between variables, we have used regression analysis and determination coefficient $R^{2}$. For variables with a high coefficient of determination, we have established a mathematical regression model, which is expressed as a system of $n$ equations:

$$
Y_{i}=\beta_{1}+\beta_{2} X 2 i+\cdots+\beta k X k i+u i, i=1,2, \cdots, n,
$$

Where:

$Y$ is the column vector of $n$ observations of the values of the described variable,

$X$ is the matrix $n x k$ observations of values of the described variables,

$\beta$ is the column vector $k$ of the unknown parameters,

$u$ is the column vector $n$ of the values of the unobserved random component.

We have examined the model using the least squares method and subsequently tested the significance of variables at $\alpha=0.1$ significance level. We have excluded all variables that 
did not comply with this provision from the model. We have carried out all calculations using the Gretl 1.9.4 and SPSS Statistics software.

\section{Results}

\section{Economic Indicators}

Among the economic indicators are indices that chiefly involve the economic dimension. This may consist directly of macroeconomic indicators, such as inflation, employment, gross domestic savings, GDP, and so on. It may also include indicators involved in shaping the economy, such as market size, consumption, corruption, business climate, and so on. For the purposes of our analysis, we have selected as indicators the Genuine Savings Index (GSI) and the Global Competitiveness Index (GCI), data for which were freely available. We have examined the course of the growth of these two indices and GDP in detail. We have found out that although GDP is growing, albeit to varying degrees, the GCI remains at more or less around the same values, while GDP growth is stronger. In contrast, the GSI follows a different trend. Its value oscillates around GDP and its fluctuations are significantly higher. The following chart shows the status of a country with respect to GDP growth and the GSI. The chart divides countries into two quadrants. Countries located in the lower quadrant, namely France and the UK, exhibit GDP growth. They are experiencing economic growth by traditional standards. However, this growth is not sustainable and develops at the expense of future generations. Furthermore, the economic growth in France is not as strong, as the GSI declines faster than growth of GDP. In the upper quadrant, there are countries in which GDP and GSI are growing and their economic growth is not at the expense of the excessive degradation of natural resources. Hungary is doing the best, as it has the highest growth of the GSI, as well as rapidly growing GDP.

Figure 1: Evaluation of countries in relation to growth of GDP and GSI

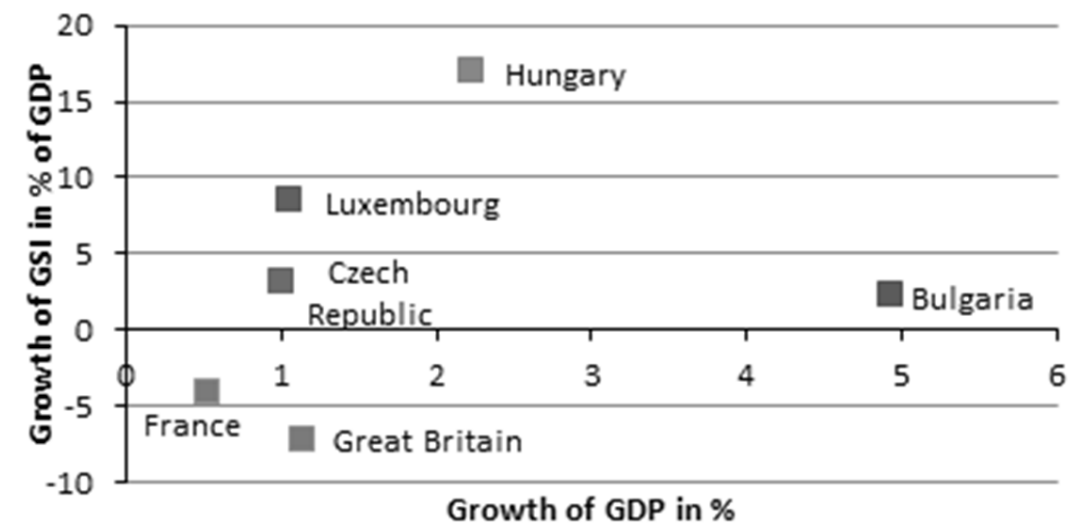

Source: Compilation by the authors based on data from the World Bank and Eurostat. 
There is a relationship between the GSI, GCI, and GDP indices. This relationship is stronger in the GSI $(\mathrm{R} 2=0.904)$ than in the GCI $(\mathrm{R} 2=0.427)$. This is because the GSI includes items that are directly related to economic development. They affect GDP, although to a lesser extent, because of expenses that we would otherwise add to GDP, but which we have deducted in the calculation of GSI.

An interesting finding is how the indices and GDP of each country change this relationship. A similar percentage of GDP growth may also explain similar behaviour within the context of indices. At the same time, there is a similar pattern between consumption and Net National Income (NNI). An example might include two opposites, such as Bulgaria and Luxembourg. Bulgaria is economically the least developed country in our study. However, among these countries, it has the highest annual increase in GDP, as it averages 7 percent per year and its consumption exceeds NNI. At the same time, the value of the regression coefficient regarding the GCI is high. In contrast, Luxembourg exhibits no strong relationship according to the correlation coefficient. Its value in relation to the GCI is 0.009 and 0.058 relative to the GSI. On the other hand, Luxembourg has the highest positive difference between consumption and adjusted net national income. We have included consumption in the analysis of economic indicators of living standards as one of the influencing factors. Consumption influenced the index of global competitiveness, rather than the index of genuine savings.

Countries with a weak relationship between the index of global competitiveness and consumption have by contrast a strong relationship between this index and average income per person. The weaker the first relationship, the more the latter grows. In countries where wages are lower and the labour market less efficient, the GCI has a higher relationship to income. There is more room for growth of both productivity and wages. In countries where this relationship is weak, the labour market is more efficient and wages are high. These countries are able to sustain high wages and the associated standard of living, but must maintain the necessary innovations, new business models, and investments. This creates more room for investment. We can therefore say that wages are important for the index of global competitiveness. Wages are derived from high labour productivity and this productivity helps to shape the advances in a country's economy. They also have a positive effect on the growth of investment and thus have an impact on raising living standards. While the Global Competitiveness Index depends on per capita income, the net savings index depends more on a person's assets. The following chart shows this relationship. From this relationship we may assume that standard of living depends just on the size of a person's assets. At the national level, the growth of these assets requires investments and savings in order to fund development. 
Figure 2: Relationship between average person's assets and GSI

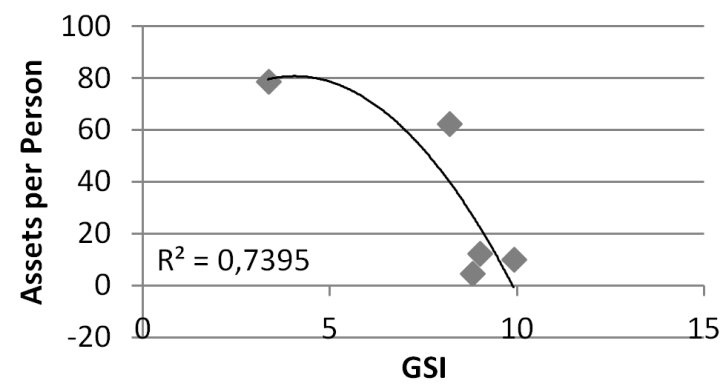

Source: Compiled by the authors based on data from a study by the Allianz Company (2012).

Another factor that we looked at within the GSI and GCI was inflation. The effect of inflation on living standards is small. In countries where the economy runs within a certain framework and inflation is kept at an acceptable level, it is not an important factor in shaping living standards.

\section{Environmental Indicators}

Environmental indicators in their indices comprise four main areas according to the following table. They include population, total damage inflicted on the environment, damage caused in the area of the environment, and the effects of such damage on quality of human life. Any such economic factors are less important and apply only to the consumption or the influence of export or import on the environment. Quality of life is expressed here as the influence of the environment. Examples might include access to safe drinking water, water quality, the impact of air pollution on human health, the impact of environmental damage on the rise and spread of diseases, the use of pesticides in agriculture, and more. This paper evaluates three environmental indicators, namely Ecological Footprint (EF), the Environmental Performance Index (EPI) and Happy Planet Index (HPI).

The development of the ecological footprint depends on the income group to which a country belongs. According to the studies by New Economic Foundation (2007), the ecological footprint developed in these countries differently. In countries with low or middle incomes, the ecological footprint per capita remained almost unchanged in contrast to high-income countries, where its value is almost three times higher and is still rising. Figure 3 shows that the relationships between the EPI and GDP, as well as between the ecological footprint and GDP, are positive. A growing GDP may increase pressure on the environment, due to the exploitation of natural resources and because of the need to dispose of waste. Apart from this factor it is also possible to consider the fact that a country needs funds to be able to remain environmentally friendly. The amount of these funds may depend on how advanced is the technology of a given country. Higher consumption increases GDP and as a result the ecological footprint as well. If consumption is taken as a major factor of welfare, an important question that arises is how to increase prosperity without an increase in material security and consumption. 
Figure 3: Relationship between EPI and GDP and relationship between GDP and ecological footprint for six selected countries
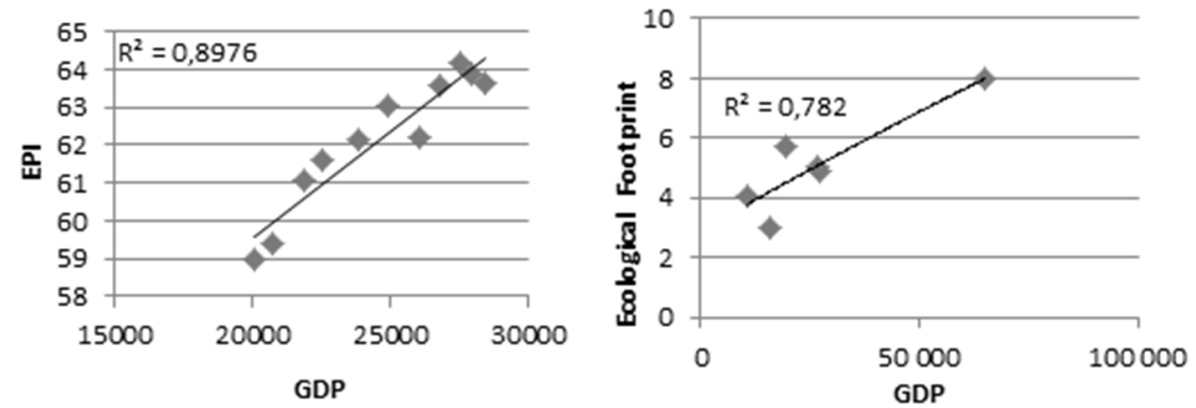

Source: Compiled by the authors and based on data from Eurostat, Yale University, and Footprint Network.

The following chart shows the position of countries in relation to their Happy Planet Index (HPI) and GDP. The ideal situation would be to have both the HPI and GDP high. This position corresponds to the upper right corner. We can see that no country falls into this quadrant. Luxembourg has a high GDP, but its HPI is not great. Bulgaria, unlike Luxembourg, has a higher HPI but significantly lower GDP. The closest is France, which has the highest HPI and also one of the highest GDP.

Figure 4: Position of selected EU countries in the matrix of GDP - HPI for 2009

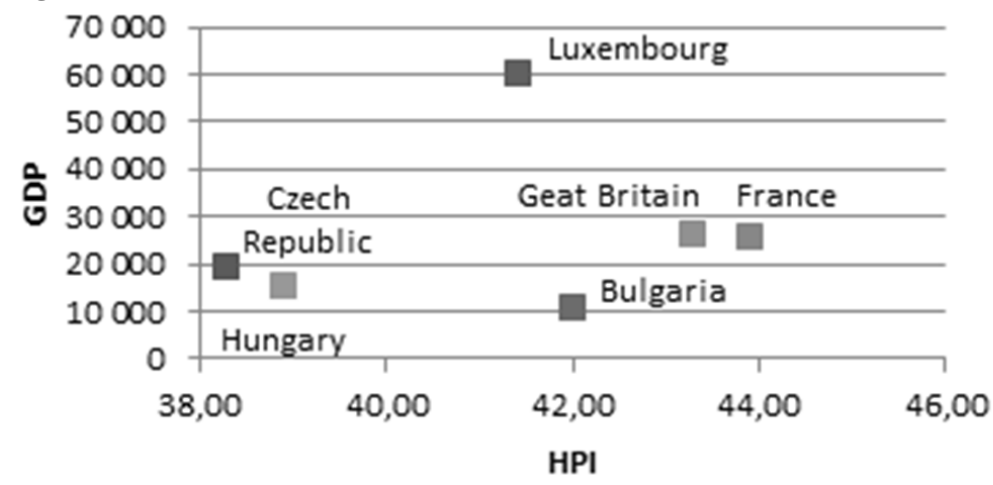

Source: Compiled by the authors and based on data from Eurostat and Happy Planet Index Organization.

Important factors in the development of environmental indices are population size and density. For example, for the Happy Planet Index, it is already included in the calculation of the ratio itself, but still plays an important role. Income groups into which countries belong are important for population growth. We assume the highest increase in population in low-income groups and the smallest in high-income groups. Whether a country is low or high income, population growth always impedes development. For the first group 
of countries, as the population grows, the available bio capacity for individual needs decreases and the country becomes more dependent on "imported" bio capacity. Middleincome countries increase fuel as well as food consumption, especially of animal products (WWF, 2008). The coefficient of correlation between the indices and the size and density of the population is significant in all cases. This means that the size of the human population affects both the environment and wellbeing, because satisfying human needs can be better or worse. The following charts show the relationship between population density and the ecological footprint, and between population size and the Environmental Performance Index.

Figure 5: Effect of population density on ecological footprint

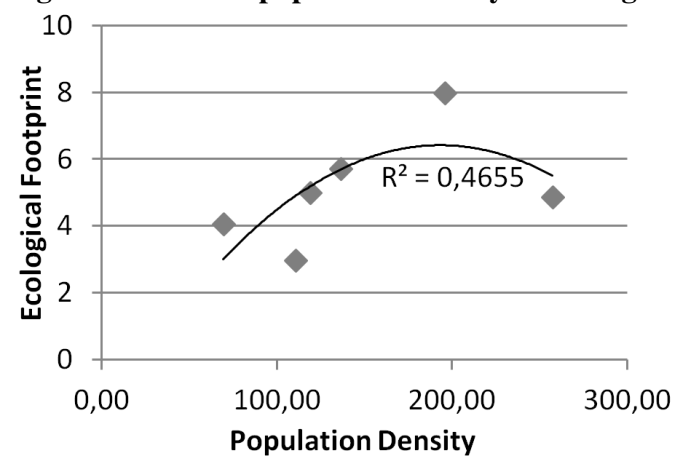

Source: Compiled by the authors and based on data from World Bank and Footprint Network.

Figure 6: Effect of population size on EPI

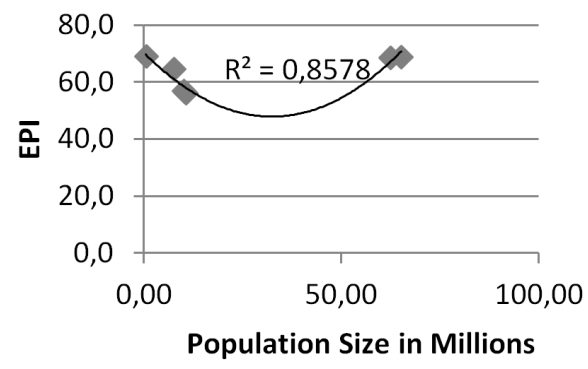

Source: Compiled by the authors and based on data from World Bank and Yale University.

If the wealth of the population is increasing, consumption and the Human Development Index are also rising, but so is the ecological footprint. The following matrix shows how the individual countries perform in the context of the ecological footprint size and in promoting their welfare (Human Development Index - HDI). The target position should be low ecological footprint and high Human Development Index, which is in the lower right corner. Countries of the European Union score highly for both variables. In addition, a country can increase its GDP through consumption of natural resources, but without any ties to the increase of prosperity. 
Figure 7: Position of countries in matrix of ecological footprint and HDI for 2010

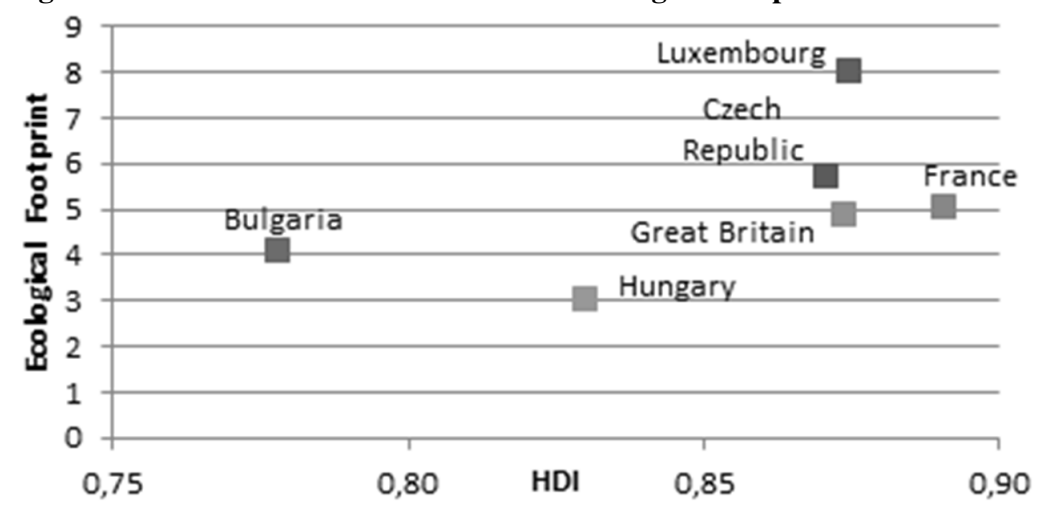

Source: Compiled by the authors and based on data from the Footprint Network and the Human Development Report Office.

The environmental Performance Index evaluates countries based on their ability to achieve environmental objectives, so it is a kind of competitiveness in the field of the environment. The EPI consists of two parts, namely environmental health and ecosystem vitality. A greater degree of correlation was achieved in environmental health. This is more connected to the country's economy than to the ecosystem vitality. Government efficiency is also very closely related to the EPI. Low bureaucracy, the creating of strategies for sustainability, and even low corruption, contribute to the better functioning of the economic system and thus to fulfilling targets.

\section{Social Indicators}

For the compilation of social indicators, we have mainly used social factors. We have selected the following indicators - the Human Development Index (HDI) and SSI. When comparing indicators dealing with living standards from the perspective of society, we can observe four main dimensions which are also the contents of these indicators. They include a long and healthy life, education, economic level, and a personal dimension. Economic factors are less important. They include GDP or the material assets of a household, such as housing standard, income, salary, and so on.

Although the Human Development Index does not include economic fundamentals, it has a strong relationship with GDP. In countries with lower GDP, the value of R2 hovers at around 0.8 . For countries with a higher GDP, the value of the correlation coefficient is at a similar level, but the relationship is not linear but logarithmic. From this fact, we can conclude that from a certain level of GDP this relationship weakens. The following chart shows the relationship between the GDP and HDI of Luxembourg. 
Figure 8: Relationship between GDP and HDI for Luxembourg

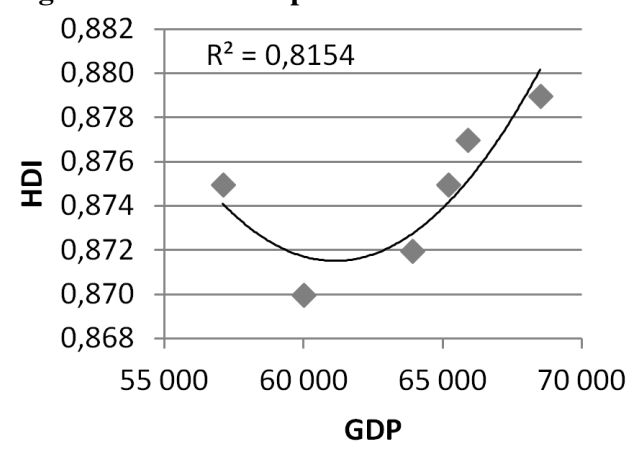

Source: Compiled by the authors and based on data from the Eurostat and UN Human Development.

The Human Development Index is criticized for the lack of any variable referring to the environment. Even though the HDI does not include such a variable, the relationship between this index and frequently monitored indicators of human activity and environmental damage, such as $\mathrm{CO} 2$ emissions, exists and is positive. Activities that send carbon dioxide into the atmosphere are those involved in the production, transport, and consumption of goods. Countries that have higher growth dynamics of the HDI also have a higher rate of growth of emissions in the air. The following chart shows the relationship between carbon dioxide emissions and the HDI.

Figure 9: Relationship between HDI and $\mathrm{CO} 2$ emissions for France

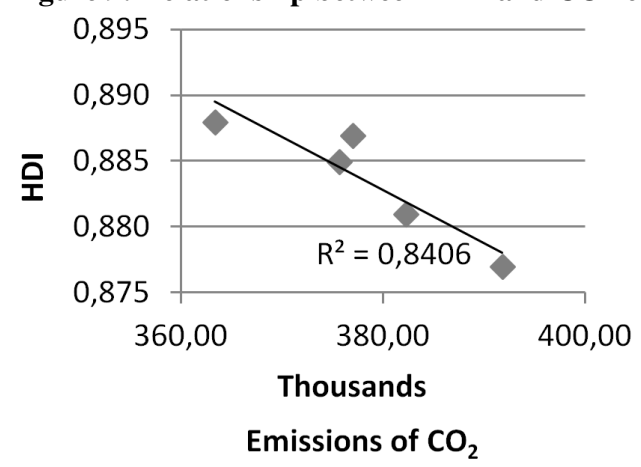

Source: Compiled by the authors and based on data from the World Bank and UN Human Development.

An item that seems to be important for human development is income inequality, expressed here by the Gini coefficient. It seems to be a significant variable in relation to the HDI. If the income equality is smaller, then the Human Development Index tends to rise. Therefore the countries that wish to have a higher income and lower income inequality should consider growth of human development a high priority. 
Both the Human Development Index and SSI are highly correlated with spending on health and education as well as income inequality. The correlation between the HDI and spending on education is 0.598 and for expenditure on health it is 0.931 . For the SSI, the correlation with spending on health is 0.821 , for spending on education it is 0.354 , while the Gini coefficient is 0.544 . Health and education as well as income inequality have a major effect on both development and welfare. A close relationship exists between the Human Development Index, SSI and the environmental sustainability index taken as an ecological equivalent for development and sustainability. The correlation coefficient between the EPI and HDI is 0.843 and between SSI and EPI, it is 0.935 .

\section{Selection of Factors}

When analysing individual groups of indicators, we have determined what is important for each area and what affects these areas. Based on these findings, it is possible to select individual items that seem to be suitable for inclusion into the newly created indicators.

Table 1: Selected Variables

\begin{tabular}{|l|c|c|}
\hline \multicolumn{1}{|c|}{ Variable } & Definition & Range of Data \\
\hline QOL & Per capita income/per capita expenses & $2000-2011$ \\
\hline Education & Total expenditure on education & $2000-2011$ \\
\hline Health care & Total expenditure on healthcare & $2000-2011$ \\
\hline GINI & Income inequality expressed as Gini coefficient & $2000-2011$ \\
\hline CO2 & Amount of carbon dioxide emissions & $2000-2011$ \\
\hline Pop_size & Population size & $2000-2011$ \\
\hline Pop_dens & Population density & $2000-2011$ \\
\hline Consumption & Magnitude of consumption & $2000-2011$ \\
\hline
\end{tabular}

Analysis of previous indicators has not produced a variable that we could consider to be equivalent to living standards and prosperity. Frequently, this variable is consumption. Consumption might be quite misleading and other factors, such as strong preferences, enter the equation. And let us not forget savings. A higher income household that prefers to save for the future may have smaller consumption than a household that earns less, but spends it all. From the second point of view, which would take into account income, the household with a higher income would be assessed as having a higher quality of life.

As a dependent variable to characterize wellbeing, we have therefore selected a variable that emerged as a mixture of two items. The first item is per capita income while the other is expenditure per person. Because different households have different incomes, they also face different expenses. However, some variables in the model did not show too much significance. Therefore, we have removed such variables from the model and created a new model. Variables that remain in the model include the density and size of the population, spending on health and education, as well as carbon dioxide emissions. The first three variables have a high degree of reliability, while $\mathrm{CO} 2$ emissions are significant at the $10 \%$ confidence level. 
The analyses performed suggest that the factors that have an impact on living standards should be integrated in the indicators of living standards. They include the size and density of the population, spending on health and education, and carbon dioxide emissions in the atmosphere. Population size reduces standard of living, leads to a higher burden on the environment and reduces sustainability. Population density influences and determines civic amenities. In more densely populated areas, all necessary services are more accessible. Such amenities include medical facilities, educational institutions, infrastructure, shopping centres, as well as areas for entertainment and leisure. However, overpopulated areas have the opposite effect. Increasing levels of health and education has an undoubted effect on the raising of living standards. Rising standards of health care lead to increasing average life expectancy and higher public satisfaction in the sense that people are able to pursue needs and interests as a result of better health. A higher level of education increases the chance of getting a better paid job, and later of obtaining a higher level of retirement support. Higher education and associated research activity lead to growth in the number of innovations, technological progress, and so on. In contrast, emissions of carbon dioxide lead to the debasing of living standards. They cause health problems as well as increase the expenses needed for additional medical care and protection of the environment and reduce comfort in problem areas. Factors identified as essential for inclusion in the evaluation of indicators of living standard are also important for consumer behaviour and preferences. Population size and density are related to the geographical characteristics of consumers. Levels of education further determine consumption patterns according to socio-economic criteria. Health determines consumer preferences, values, and spending habits. For future research to assess living standards, it would be appropriate to supplement the fundamental statistical data with qualitative research. Statistical data separating significant and irrelevant variables and questionnaires would complement research in general.

\section{Conclusion}

Numerous publications indicate that the standard of living of a population is mainly influenced by economic, environmental, and social factors. For the present contribution to the expression of the influence of economic factors, we have selected and analysed several indicators. They included the Genuine Savings Index (GSI) and Global Competitiveness Index (GCI). We have noted their relationship and relation to GDP and consumption as well as to net national income (NNI). The results of our analyses indicate that, while the GCI reveals dependence on per capita income, the GSI shows dependence on people's assets. At the national level, the growth of these assets requires investment and savings in order to finance development. To reveal the impact of environmental factors, we have evaluated three indicators, namely Ecological Footprint (EF), the Environmental Performance Index (EPI) and Happy Planet Index (HPI).

The analysis revealed that, for a given status of environmental indicators and their development, the most important are population size and density. We have expressed and analysed social factors using the Human Development Index (HDI) and SSI. The most important for human development seem to be income inequality, as well as expenditure on health and education. Analysis of the monitored indicators did not lead to the discovery of a unique 
variable that could be equivalent to the living standard. We have excluded some variables from the study. Variables that significantly affect living standards include population size and density, expenditure on health care and education, as well as the negative effect of carbon dioxide emissions.

On the whole, the factors that affect standard of living and which should be included in the indicators are population size and density, expenditure on health and education and the emission of carbon dioxide into the atmosphere. Population size reduces living standards and leads to a greater burden on the environment and also reduces sustainability. Population density influences and determines civic amenities. In more densely populated areas, all necessary services are more accessible. Such amenities include medical facilities, educational institutions, infrastructure, shopping centres, as well as areas for entertainment and leisure. However, overpopulated areas have the opposite effect. Increasing levels of health and education have an undoubted effect on the raising of living standards.

Rising standards of health care lead to increasing average life expectancy and higher public satisfaction in the sense that people are able to pursue needs and interests as a result of better health. A higher level of education increases the chances of getting a better paid job, and later of obtaining a higher level of retirement support. Higher education and associated research activity lead to the growth of the number of innovations, technological progress, and so on. In contrast, emissions of carbon dioxide lead to the debasing of living standards. They cause health problems as well as increase the expenditure needed for additional medical care and protection of the environment and reduce comfort in problem areas. Factors identified as essential for inclusion in the evaluation of indicators of living standard are also important for consumer behaviour and preferences. Population size and density are related to the geographical characteristics of consumers. Levels of education further determine consumption patterns according to socio-economic criteria. Health determines consumer preferences, values, and spending habits. For future research to assess living standards, it would be appropriate to supplement the fundamental statistical data with qualitative research. Statistical data separating significant and irrelevant variables and questionnaire surveys will complement research in general.

The results of this paper and other results of the research activities by the authors indicate that criticism of per capita GDP as an indicator of living standards is justified. This is due to the fact that it really cannot reflect all those factors which influence quality of life. Finding an index which would comprehensively deal with this topic seems problematic. Despite all the new, emerging, alternative ways, there is still none that would satisfy the demands of professionals from various fields. Needless to say, we have much research ahead of us.

\section{Acknowledgements}

We thank Klara Bošanská for her useful work in support of this paper. 


\section{References}

Bennett, M. K. (1937). On Measurement of Relative National Standards of Living. The Quarterly Journal of Economics [online], 51(2). DOI: 10.2307/1882091.

Bleys, B. (2012). Beyond GDP: Classifying alternative measures for progress. Social Indicators Research, 109(3), 355-376.

Cottam, H. R. and Mangus, A. R. (1942). A Proposed Definition of Standard of Living. Social Forces [online], 21(2), 177-179. DOI: 10.2307/2570553.

Hebák, P., Hustopecký, J. Pecáková, I., Průša, M., Řezánková, H., Vlach, P., Svobodová, A. (2005). Vícerozměrné statistické metody. Informatorium.

Krugman, P. R. and Wells, R. (2012). Macroeconomics (3rd ed). New York: Worth Publishers.

Meloun, M., Militký, J. (2006). Kompendium statistického zpracování dat (2nd ed). Prague: Academia.

Sen, A. (1989). The Standard of Living. Cambridge University Press.

Spěváček, V. (2005). Ekonomický růst České republiky ve světle ukazatelů reálného důchodu [online]. Centrum ekonomických studií VŠEM. Retrieved January 19, 2013, from http://www.vsem.cz/data/data/ces-soubory/working-paper/gf_WPNo2.pdf.

WWF. (2008). Living Planet Report 2008 [online]. Retrieved from http://www.wwf.se/source.php/1199652/Living\%20Planet\%20Report\%202008.pdf. 